\title{
Comparative analysis of HPV DNA and LBC for screening of cervical cancer in women with unhealthy cervix
}

\author{
Shreya Raj, Mala Srivastava \\ Corresponding author: Dr. Shreya Raj, Senior resident at Dr Baba Saheb Ambedkar Medical \\ College and Hospital, New Delhi, India; Email : raj.shreya@yahoo.com
}

Distributed under Attribution-Non Commercial - Share Alike 4.0 International (CC BY-NC-SA 4.0)

\begin{abstract}
Background: The cervical cancer is one of the leading cause of cancer death among women in developing and developed countries. Screening for cervical cancer is essential as the women are often asymptomatic and it also reduces both the incidence and mortality of the cancer cervix if detected in early stage. Objectives: We aimed to determine sensitivity and specificity of liquid based cytology (LBC) and HPV DNA to detect pre-neoplastic and neoplastic lesions of cervix. Methods: This was a prospective observational study including 506 women of reproductive, perimenopausal and postmenopausal age group who presented with abnormal vaginal discharge, post coital bleeding, abnormal uterine bleeding, postmenopausal bleeding or had unhealthy cervix on examination, who were subjected to screening by doing LBC and HPV DNA testing. The diagnosis of LBC and HPV DNA was compared against the gold standard of cervical biopsy. The data was entered in MS Excel and analysed using SPSS ver 21.0. A p $<0.05$ was considered as significant. Results: The mean age of patients in the study was 43.36 years. The sensitivity and specificity of LBC was $76.47 \%, 43.85 \%$, and that of HPV DNA was $88.23 \%, 57.89 \%$. The co-testing of LBC and HPV-DNA had a sensitivity and specificity of $94.11 \%$ and $24.56 \%$. Discriminatory power of LBC (AUC 0.6; $95 \%$ CI: 0.48 to 0.71 ) and HPV DNA (AUC 0.73; 95\% CI: 0.61 to 0.83 ) was acceptable. Among all the parameters, HPV DNA was the best predictor of pre-invasive or invasive lesion with $73.00 \%$ chances of correctly predicting pre-invasive or invasive lesion. Conclusion: Though the early detection and treatment of pre-invasive and invasive lesion of cervix is required, it is important that the best and most sensitive diagnostic tools are used for the screening purposes. Overall HPV DNA was best predictor of pre-invasive or invasive lesion with significantly higher diagnostic accuracy as compared to co-testing.
\end{abstract}

Keywords: Cervical cancer, liquid based cytology, HPV DNA.

The cervical cancer is a leading cause of cancer death among women, resulting in major cause of mortality and morbidity ${ }^{1}$. It is the second most common cancer in women of less developed countries with nearly 570,000 new cases in 2018 (84\% of the new cases worldwide $)^{2}$. Cervical cancer screening has been advocated considering that it may reduce the mortality and morbidity associated with the cancer ${ }^{3-6}$. A plethora of screening techniques have been applied which include pap smear, liquid based cytology (LBC) and human papilloma virus (HPV) testing ${ }^{7}$. The variation in quality of the conventional pap smear is quiet substantial and this might influence the detection rate of high grade CIN, hence,
LBC has been introduced. In addition, LBC carries the advantages of faster reporting, less missing out of cases and application of HPV testing from the remnant fluid ${ }^{7}$.

The history of LBC dates back to 1996, when Thin Prep ${ }^{\circledR}$ was first approved by US Food and Drug Administration (USFDA) ${ }^{8}$. Since then it has gained popularity in terms of clinical benefit/versatility and is now used in over $90 \%$ cases in USA; ${ }^{9}$ however, it also suffers from false negative results in a small proportion.

To further serve the purpose, HPV DNA testing (molecular based studies) have shown better sensitivity in identifying the risk of cervical cancer ${ }^{10,11}$. The use of HPV

Received: $28^{\text {th }}$ September 2020, Peer review completed: $15^{\text {th }}$ February 2021, Accepted: $3^{\text {rd }}$ March 2021.

Raj S, Srivastava M. Comparative analysis of HPV DNA and LBC for screening of cervical cancer in women with unhealthy cervix. The New Indian Journal of OBGYN. 2022; 8(2): 166-73. 
The New Indian Journal of OBGYN. 2021 (January-June);8(2)

testing as a primary screen has shown promise in developing countries but remains experimental due to its high cost ${ }^{12,13}$. High risk HPV screening is highly sensitive, but specificity depends on subsequent evaluation strategies and screening frequencies ${ }^{11-14}$.

The present study aims to evaluate and compare the efficacy of LBC and HPV as a screening modality in diagnosing the pre-invasive and invasive lesions of cervix. The study results may help guide the use of HPV DNA testing as an additive for cervical cancer screening.

\section{Methods}

This prospective observational study was conducted for duration of 18 months. A total of 506 women of reproductive, perimenopausal, and postmenopausal age group with unhealthy cervix and who presented with the complaints of abnormal vaginal discharge, postcoital bleeding, abnormal uterine bleeding, and postmenopausal bleeding were included after obtaining an informed consent. Pregnant women and hysterectomized patients were excluded from the study.

A detailed history of the women including age, age at first sex and marriage, family history, socioeconomic history and personal history (hygiene and addictions to drugs), presenting complaints, obstetric outcome, marital history/ number of sexual partners, use of contraceptives were taken.

After obtaining the history, a general physical examination and systemic examination was carried out. Per speculum examination was performed to note any abnormality on direct visual inspection of the cervix without magnification. For each women, LBC and HPV DNA testing was done.

LBC reporting was done by modified Bethesda system (2001). Cytology was considered positive if it revealed any of the following lesions - atypical squamous cells of undetermined significance (ASCUS) and ASC-H, low grade squamous intraepithelial lesions (LSIL), high grade squamous intraepithelial lesions (HSIL) or cells suspicious of malignancy. Negative smears included those with normal and inflammatory report.

HPV DNA testing was done by hybrid capture testing (principle of chemiluminescence). Sure path hybrid capture II technique was used for detection for high risk HPV DNA $(16,18,31,33,35,39,45,51,52,56,58,59,68)$. Clinical interpretation of HPV results was done on the basis of relative light units (RLU). ${ }^{14}$ The report was expressed as negative HPV-RLU/ cut off ratio $<1.0$; positive HPV- RLU/ cut off $>1.0 ; 1 \mathrm{RLU}=5000$ copies of DNA. Histopathology/cervical biopsy was taken as the gold standard for cervical cancer for comparison of the findings of LBC and HPV DNA.

Statistical analysis: Categorical variables were presented in number and percentage (\%). Qualitative variables were associated using Chi-Square test/Fisher Exact test. Diagnostic accuracy was compared using Chi square test. A $p$ value of $<0.05$ was considered statistically significant. The data was entered in MS EXCEL spread sheet and analysis was done using Statistical Package for Social Sciences (SPSS) version 21.0.

\section{Results}

Table 1 shows the sociodemographic profile of the patients. Majority of the patients $(22.10 \%)$ were $36-40$ years of age, followed by $20.80 \%$ patients each in age groups 41 45 and 46-50 years. Most of the patients were para 2 $(50.60 \%)$, followed by para $3(28.50 \%)$, and para $1(9.90 \%)$.

\begin{tabular}{|c|c|c|}
\hline $\begin{array}{l}\text { Socio demographic } \\
\text { characteristics }\end{array}$ & Number & Percentage \\
\hline \multicolumn{3}{|l|}{ Age } \\
\hline $22-25$ years & 3 & $0.60 \%$ \\
\hline $26-30$ years & 25 & $4.90 \%$ \\
\hline $31-35$ years & 63 & $12.50 \%$ \\
\hline $36-40$ years & 112 & $22.10 \%$ \\
\hline $41-45$ years & 105 & $20.80 \%$ \\
\hline $46-50$ years & 105 & $20.80 \%$ \\
\hline$>50$ years & 93 & $18.40 \%$ \\
\hline \multicolumn{3}{|l|}{ Parity } \\
\hline P0 & 2 & $0.40 \%$ \\
\hline $\mathrm{P} 1$ & 50 & $9.90 \%$ \\
\hline $\mathrm{P} 2$ & 256 & $50.60 \%$ \\
\hline P3 & 144 & $28.50 \%$ \\
\hline $\mathrm{P} 4$ & 48 & $9.50 \%$ \\
\hline P5 & 4 & $0.80 \%$ \\
\hline P6 & 2 & $0.40 \%$ \\
\hline \multicolumn{3}{|l|}{ Class } \\
\hline I & 2 & $0.40 \%$ \\
\hline II & 11 & $2.20 \%$ \\
\hline III & 75 & $14.80 \%$ \\
\hline IV & 223 & $44.10 \%$ \\
\hline $\mathrm{V}$ & 195 & $38.50 \%$ \\
\hline \multicolumn{3}{|l|}{ Age at marriage } \\
\hline $17-20$ years & 130 & $25.70 \%$ \\
\hline $21-25$ years & 332 & $65.60 \%$ \\
\hline 26-30 years & 44 & $8.70 \%$ \\
\hline $31-35$ years & 0 & $0.00 \%$ \\
\hline$>35$ years & 0 & $0.00 \%$ \\
\hline \multicolumn{3}{|l|}{ Method } \\
\hline None & 214 & $42.30 \%$ \\
\hline Barrier & 112 & $22.10 \%$ \\
\hline Ligation & 111 & $21.90 \%$ \\
\hline Intra uterine contraceptive device & 36 & $7.10 \%$ \\
\hline Oral contraceptive pill & 33 & $6.50 \%$ \\
\hline Vasectomy & 0 & $0 \%$ \\
\hline
\end{tabular}

$65.6 \%$ patients were 21-25 years of age at the time of marriage (table 1). Method of contraception was barrier in $22.10 \%$ patients, ligation in $21.90 \%$, intrauterine 
contraceptive device in $7.10 \%$, and oral contraceptive pill in $6.50 \%$ patients.

\begin{tabular}{lll} 
Table 2: Distribution of clinical examination findings. \\
\hline Clinical examination findings & Number & Percentage \\
\hline Clinical sign & 131 & \\
Cervical ectropion & 427 & $25.88 \%$ \\
Hypertrophy & 25 & $84.38 \%$ \\
Nabothian follicles & 10 & $4.94 \%$ \\
Cervical polyp & 0 & $1.97 \%$ \\
Ulcer & 0 & 0 \\
Leukoplakia & 2 & 0 \\
Growth over cervix & & $0.39 \%$ \\
\hline P/V examination & 55 & \\
Normal & 336 & $10.86 \%$ \\
Multiparous size & 99 & $66.40 \%$ \\
Uterus 8- 10 weeks size & 3 & $19.56 \%$ \\
Uterus 10-12 weeks size & 7 & $0.59 \%$ \\
Uterus 12-14 weeks size & 6 & $1.38 \%$ \\
Uterus $>14$ weeks size & & $1.18 \%$ \\
\hline
\end{tabular}

Table 3: Distribution of diagnosis findings.

\begin{tabular}{lcc}
\hline Diagnosis findings & Number & Percentage \\
\hline Cytological diagnosis & & \\
Normal & 211 & $41.69 \%$ \\
Inflammatory & 246 & $48.61 \%$ \\
ASCUS & 25 & $4.94 \%$ \\
ASC-H & 4 & $0.79 \%$ \\
LSIL & 6 & $1.18 \%$ \\
HSIL & 6 & $1.18 \%$ \\
AGUS & 2 & $0.39 \%$ \\
Endometrial cell & 4 & $0.79 \%$ \\
Cancer & 2 & $0.39 \%$ \\
\hline Result & & \\
hrHPV DNA positive & 39 & $7.70 \%$ \\
hrHPV DNA negative & 467 & $92.29 \%$ \\
\hline Appearance & & \\
Normal & 23 & $31.08 \%$ \\
Acetowhite area & 45 & $60.81 \%$ \\
Mosaic/ Punctuation & 3 & $4.05 \%$ \\
Abnormal vessels & 4 & $5.40 \%$ \\
Rolled margins & 0 & $0.00 \%$ \\
Iodine negative area & 40 & $54.05 \%$ \\
unsatisfactory & 4 & $5.40 \%$ \\
\hline Microscopic observation & & \\
Normal & 0 & $0.00 \%$ \\
Chronic cervicitis & 57 & $77.02 \%$ \\
CIN - I & 6 & $8.10 \%$ \\
CIN - II & 2 & $2.70 \%$ \\
CIN - III & 3 & $4.05 \%$ \\
Carcinoma in situ & 1 & $1.35 \%$ \\
Invasive cancer & 5 & $6.75 \%$ \\
\hline ASCUS - Atypical squamous cells of undetermined significance, ASC-H \\
- Atypical squamous cells - high grade, LSIL - Low grade squamous \\
intraepithelial lesions, HSIL & - high grade squamous \\
lesions, CIN - Cervical intraepithelial neoplasia. & \\
\hline & & \\
& &
\end{tabular}

The presenting symptoms included discharge per vaginum in $43.87 \%$ patients, low back pain/pain in lower abdomen in $43.67 \%$ patients, and AUB in $35.37 \%$ patients (figure 1). On clinical examination, hypertrophy, cervical ectropion, nabothian follicles, cervical polyp, and growth over cervix were present in $84.38 \%, 25.88 \%, 4.94 \%, 1.97 \%$, and $0.39 \%$ patients, respectively. Per vaginal examination revealed uterus was multiparous size in $66.40 \%, 8-10$ weeks size in $19.56 \%, 10-12$ weeks size in $0.59 \%, 12-14$ weeks size in $1.38 \%$, and $>14$ weeks size in $1.18 \%$ patients (table 2 ).

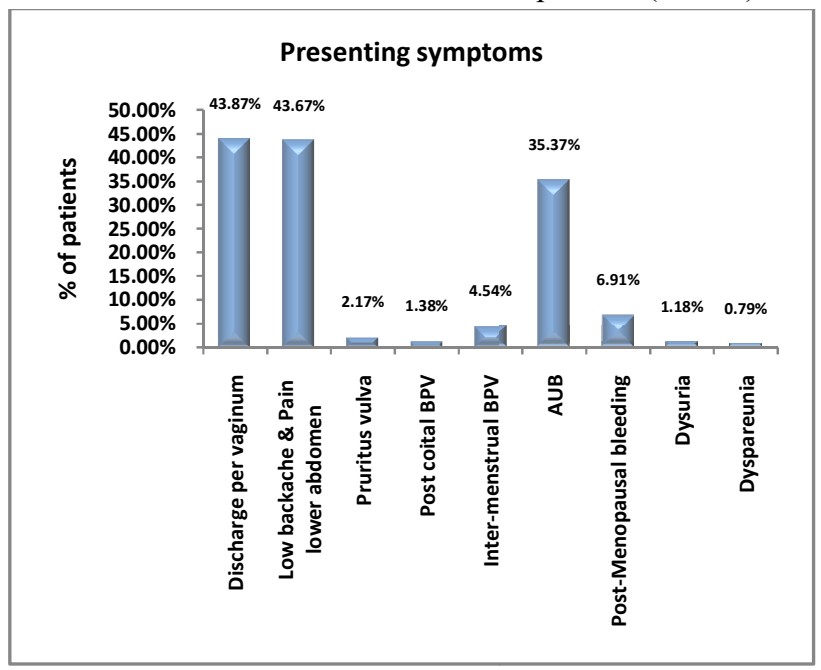

Figure 1: Distribution of presenting symptoms

On LBC, out of 461 negative reports 211 were reported as normal and 246 as inflammatory and 4 as endometrial cells. Among 45 abnormal reports, 4.94\% were ASCUS, 1.18\% were LSIL, $1.18 \%$ were HSIL, $0.79 \%$ were ASC-H, 0.39\% were AGUS, and $0.39 \%$ were found to have cancer. HPV DNA was negative in majority of the cases (92.29\%) and only $39(7.7 \%)$ were found to be HPV DNA positive.

Colposcopy was performed in 74 women who presented with persistent vaginal discharge, or post coital bleeding or were positive on LBC or HPV DNA or both. Normal findings were reported in $23(31.08 \%)$ and rest were abnormal, most common abnormality being acetowhite area $(60.81 \%)$ and iodine negative area (54.05\%). Maximum number of women $(77.02 \%)$ had chronic cervicitis. CIN I was reported in $8.10 \%$, CIN II in $2.70 \%$, CIN III in $4.05 \%$ women. There was 1 patient $(1.35 \%)$ with carcinoma in situ and 5 women $(6.75 \%)$ with invasive carcinoma (table 3 ).

There was a significant association between LBC and HPV. Compared to HPV negative cases, HPV positive cases had significantly less cases that were normal/inflammatory (13 vs. 444, $\mathrm{p}<0.0001)$ and low grade (15 vs. 16, $\mathrm{p}<0.0001)$; but significantly more cases with high grade cervical lesions ( 8 vs. $2, \quad \mathrm{p}<0.0001)$ and cancer ( 2 vs. $0, \mathrm{p}$ $=0.006$ ) (table 4). 
There was a significant association between microscopic observation and HPV. Compared to HPV negative cases, HPV positive cases had significantly less chronic cervicitis cases ( 24 vs. $33, \mathrm{P}<.0001$ ), but significantly more CIN I cases ( 5 vs. $1, \mathrm{p}<0.0001), \mathrm{CIN}-\mathrm{II}(5$ vs. $0, \mathrm{p}<0.0001)$, and cancer ( 5 vs. $1, \mathrm{p}<0.0001)$ (table 5).

Table 4: Association of LBC and HPV

\begin{tabular}{llll}
\hline LBC & $\begin{array}{l}\text { Number of } \\
\text { HPV positive } \\
\text { cases (N=39) }\end{array}$ & $\begin{array}{l}\text { Number of } \\
\text { HPV negative } \\
\text { cases }\end{array}$ & $\begin{array}{l}\text { P } \\
\text { value }\end{array}$ \\
\hline Normal/Inflammatory & 13 & 444 & $<.0001$ \\
Low grade & 15 & 16 & $<.0001$ \\
High grade & 8 & 2 & $<.0001$ \\
Cancer & 2 & 0 & 0.006 \\
Endometrial cells & 1 & 5 & 0.383 \\
\hline
\end{tabular}

Discriminatory power of LBC (AUC $0.6 ; 95 \%$ CI: 0.48 to 0.71 ) and HPV DNA (AUC 0.73 ; 95\% CI: 0.61 to 0.83 ) was acceptable. Among all the parameters, HPV DNA was the best predictor of pre-invasive or invasive lesion with $73.00 \%$ chances of correctly predicting pre-invasive or invasive lesion.

\begin{tabular}{llll}
\multicolumn{4}{l}{ Table 5: Association of microscopic observation and HPV } \\
\hline Microscopic & No. of HPV & No. of HPV & P \\
observation & positive cases & negative cases & value \\
\hline Chronic cervicitis & 24 & 33 & $<.0001$ \\
CIN I & 5 & 1 & $<.0001$ \\
CIN - II & 5 & 0 & $<.0001$ \\
Cancer & 5 & 1 & $<.0001$ \\
\hline
\end{tabular}

the maximum predictive value i.e. maximum diagnostic accuracy. So overall HPV DNA was best predictor of preinvasive or invasive lesion with significantly higher diagnostic accuracy as compared to co-testing (table 6).

\section{Discussion}

The application of screening programs has brought down the incidence and mortality of cervical cancer in some developed countries 15, 16. However among developing countries, reports have been conflicting ${ }^{17-19}$. On evaluating performance of screening programs for cervical cancer in various countries, it became evident that the service capability of health care facilities in different regions, laboratory test conditions, the number of cytological readers, and acceptance as well as satisfaction of population with screening methods influence the efficacy of large scale screening of population ${ }^{19-22}$.

LBC has been developed to address the sampling problems of conventional pap smear ${ }^{23}$. A high false negative rate has increased the problems inherent in cytological screening. Molecular techniques have been required to reduce the false negative rate, identify the earlier stages of infection and thus, improve follow up because most infections are not microscopically evident ${ }^{24}$. The widely used alternative for cervical cancer screening is HPV DNA

Table 6: Sensitivity, specificity, NPV and PPV of LBC, HPV DNA and co-testing to predict pre-invasive or invasive lesion and comparison of their diagnostic accuracy.

\begin{tabular}{|c|c|c|c|}
\hline Parameters & LBC & HPV DNA & $\begin{array}{l}\text { Co-testing } \\
\text { (LBC and HPV DNA) }\end{array}$ \\
\hline Sensitivity $(95 \% \mathrm{CI})$ & $76.47 \%(50.10 \%$ to $93.19 \%)$ & $88.24 \%(63.56 \%$ to $98.54 \%)$ & $94.12 \%(71.31 \%$ to $99.85 \%)$ \\
\hline Specificity $(95 \% \mathrm{CI})$ & $43.86 \%(30.74 \%$ to $57.64 \%)$ & $57.89 \%(44.08 \%$ to $70.86 \%)$ & $24.56 \%(14.13 \%$ to $37.76 \%)$ \\
\hline AUC $(95 \% \mathrm{CI})$ & $0.6(0.48$ to 0.71$)$ & $0.73(0.61$ to 0.83$)$ & $0.59(0.47$ to 0.71$)$ \\
\hline Positive Predictive Value $(95 \% \mathrm{CI})$ & $28.89 \%(16.37 \%$ to $44.31 \%)$ & $38.46 \%(23.36 \%$ to $55.38 \%)$ & $27.12 \%(16.36 \%$ to $40.27 \%)$ \\
\hline Negative Predictive Value $(95 \% \mathrm{CI})$ & $86.21 \%(68.34 \%$ to $96.11 \%)$ & $94.29 \%(80.84 \%$ to $99.30 \%)$ & $93.33 \%(68.05 \%$ to $99.83 \%)$ \\
\hline Diagnostic accuracy & $51.35 \%$ & $64.86 \%$ & $40.54 \%$ \\
\hline LBC vs HPV DNA & 0.134 & & \\
\hline LBC vs Co-testing & 0.248 & & \\
\hline HPV DNA vs Co-testing & 0.005 & & \\
\hline
\end{tabular}

Co-testing (LBC and HPV DNA) had sensitivity of 94.12\% followed by HPV DNA (88.24\%), LBC (76.47\%). In prediction of pre-invasive or invasive lesion, LBC had lowest sensitivity of $76.47 \%$. On the other hand, HPV DNA had specificity of $57.89 \%$ followed by LBC (43.86\%), and co-testing $(24.56 \%)$. In prediction of pre-invasive or invasive lesion, co-testing had lowest specificity of $24.56 \%$.

The positive predictive value $(38.46 \%)$ and negative predictive value $(94.29 \%)$ was highest for HPV DNA testing. There is always a trade-off between sensitivity and specificity (any increase in sensitivity will be accompanied by a decrease in specificity). So we choose that variable as best in which combination of sensitivity and specificity gives testing which identifies women with papilloma virus infections. The present study was conducted to compare HPV DNA and LBC for screening of cervical cancer in women with unhealthy cervix.

Median age of screened population in present study was 43.36 years, which co-related well with the study of Karimi Zarchi et al ${ }^{25}$ and Ronco et al ${ }^{26}$ where median age was 42 and 45 years respectively.

Multiparity is a known risk factor of cervical cancer which may be attributable to nutritional and hormonal changes occurring in pregnancy, immune suppression in pregnancy, and cervical trauma during vaginal delivery ${ }^{27}$. In present study, majority were multiparous, mean parity being 
2.40, which co-related well with the study of Suguna M et $\mathrm{al}^{28}$ as most of the patients were multiparous.

There is a definite co-relation between early age at intercourse and cervical carcinogenesis as evident in a metaanalysis ${ }^{29}$. In our study maximum number of patients 332 $(65.60 \%)$ had their marriage (i.e first sexual debut) between 21-25 years of age. Findings of present study were in accordance with the study of Zhao $\mathrm{H}$ et al ${ }^{30}$ with respect to the mean age at marriage (21.77 years).

In present study, maximum number of patients (42.3\%) did not use any method of contraception, $22.1 \%$ patients were using barrier method, and $21.9 \%$ were ligated. Ashmita $\mathrm{D}$ et al ${ }^{31}$ also showed that maximum numbers of patients were not using any contraceptive and $6.5 \%$ were on OCP.

Women with cervical cancer may be asymptomatic or they may present with symptoms like excessive vaginal discharge, foul smelling discharge, irregular or inter menstrual bleeding, post coital bleeding or postmenopausal bleeding. Majority of the patients $(43.87 \%)$ presented with discharge per vaginum followed by $43.67 \%$ with low backache and pain lower abdomen. Suguna $M$ et al ${ }^{28}$ and Gopal $\mathrm{N}$ et al ${ }^{27}$ reported similar findings as white discharge as their major symptom. Other common symptoms were irregular bleeding and postcoital bleeding.

Shankaranarayana et al ${ }^{32}$ stated that visual inspection of the cervix is an art, neglected in the recent years in reference to cytological screening, which will reveal characteristic signs of early lesions of dysplasia. In present study, $84.38 \%$ patients had hypertrophied cervix followed by $25.88 \%$ with cervical ectropion. Shankaranarayana et al ${ }^{32}$ found that cervicitis was the most common finding and Gopal $\mathrm{N}$ et al ${ }^{27}$ reported that maximum number of patients had ectropion.

Between the two common methods of screening of cervical cancer (LBC and HPV DNA), American Society for Colposcopy and Cervical Pathology (ASCCP) recommends combination screening rather than use of either alone ${ }^{33}$. Thereby we assessed and compared the individual methods along with the combination of methods to find the better accuracy among them.

In the present study, $91.10 \%$ patients were negative on cytology, 4.94\% had ASCUS, $1.18 \%$ had LSIL, 1.18\% had HSIL, $0.79 \%$ had ASC-H, and $0.39 \%$ had AGUS. These findings are in accordance with Junyangdikul $\mathrm{P}$ et al ${ }^{24}$ where $87.96 \%$ patients were negative on cytology, $4.80 \%$ had ASCUS, $1.07 \%$ had HSIL, and $0.77 \%$ had ASC-H. Similarly, Agorastos $\mathrm{T}$ et al ${ }^{34}$ found negative on cytology in $94.7 \%$ patients, $1.9 \%$ had LSIL, and $0.4 \%$ patients had AGUS.
In the present study, $7.70 \%$ women tested positive for high risk HPV as tested by DNA hybrid capture II technique. Present study co-related well with the study of Ronco et al ${ }^{26}$, Ogilive GS et $\mathrm{al}^{35}$ and $\mathrm{Zhao} \mathrm{FH}$ et $\mathrm{al}^{30}$ with respect to the prevalence of HPV DNA infection.

In the present study, 74 patients underwent colposcopic examination. Screen-positive subjects and screen-negative patients with persistent vaginal discharge and postcoital bleeding were subjected to colposcopic evaluation. About $31.08 \%$ patients had normal colposcopy, aceto-white area was found in $60.81 \%$, and iodine negative area in $54.05 \%$ patients. There was more than one colposcopic finding in some of the patients. Present study was comparable to the study of Ramesh $\mathrm{G}$ et al ${ }^{36}$ with respect to the colposcopic findings. Maximum number of patients had aceto-white area as an abnormal finding on colposcopy.

Present study co-related well with the study of Gopal N et $\mathrm{al}^{27}$ where CIN I was present in $8.10 \%$, and CIN II and CIN III in $2.70 \%$ and $4.05 \%$ respectively. Present study was also in accordance with the study of Suguna et $\mathrm{al}^{28}$ and Pravin $\mathrm{S}$ et $\mathrm{al}^{37}$ with respect to histopathological diagnosis of invasive cancer which in our study was $6.75 \%$.

A significant association was observed between LBC and HPV as among normal/inflammatory cases, 2.84\% (13/457) were HPV positive; in low grade, $48.39 \%$ (15/31) were HPV positive; among High grade, 20\% (2/10) were HPV positive; 2 cancer cases were HPV positive; and out of 6 Endometrial cells, 1 was HPV positive and 5 HPV negative. A significant association was also found between microscopic observation and HPV as in chronic cervicitis cases, 42.1\% (24/57) were HPV positive; in 6 CIN I cases, 5 were HPV positive; all 5 CIN - II cases were HPV positive; and among 6 cancer cases, 5 were HPV positive and $1 \mathrm{HPV}$ negative. Ma Y et al, ${ }^{19}$ included total 9,972 cases with cervical cancer and found that the overall prevalence of positive results by HPV and $\mathrm{LBC}$ was $7.5 \%$ and $3.1 \%$, respectively. There were statistically significant differences in the total detection rate of CIN2+ between LBC and HPV groups $(\mathrm{P}=0.007)$. In study by Wang $\mathrm{J}$ et al, ${ }^{38}$ positive result was shown by LBC in $32.9 \%$ and HPV in $37.8 \%$ cases. Total 1178 patients had cervicitis or other benign lesion; LBC and HPV showed positive results in $9.4 \%$ and $13.4 \%$ cases, respectively. LBC and HPV showed positive results in $64.9 \%$ and $71.9 \%$ cases, respectively in total 473 cases of CIN1, in $81.8 \%$ and $89.8 \%$ cases, respectively in total 137 cases of CIN2, in $92.9 \%$ and $95.2 \%$ cases, respectively in total 84 cases of CIN3, and all 12 cases of cervical carcinoma were positive on LBC and 
The New Indian Journal of OBGYN. 2021 (January-June);8(2)

HPV. There was a significant association between LBC and HPV.

In the present study, sensitivity, specificity, AUC, PPV, NPV, and diagnostic accuracy for LBC were $76.47 \%$, $43.86 \%, 0.6,28.89 \%, 86.21 \%$, and $51.35 \%$; for HPV DNA were $88.24 \%, 57.89 \%, 0.73,38.46 \%, 94.29 \%$, and $64.86 \%$; and for co-testing (LBC and HPV DNA) were 94.12\%, $24.56 \%, 0.59,27.12 \%, 93.33 \%$ and $40.54 \%$. The sensitivity and specificity of HPV test was higher compared to that of LBC and with the combination of both sensitivity was increased but specificity was much reduced. Among other studies, Wang $\mathrm{J}$ et $\mathrm{al}^{38}$ found that sensitivity, specificity, AUC, PPV, NPV, and diagnostic accuracy for LBC were $86.7 \%, 74.7 \%, 0.807,32.6 \%, 97.5 \%$, and $74.7 \%$; for $\mathrm{HPV}$ DNA were $92.3 \%, 69.8 \%, 0.810,30.2 \%, 98.5 \%$, and $72.6 \%$; and for co-testing (LBC and HPV DNA) were 98.7\%, $60.8 \%, 0.797,65.4 \%, 26.2 \%$ and $99.7 \%$. The sensitivity of HPV test was higher compared to that of LBC; however, specificity was lesser than that of LBC. This implies that HPV test was better in detecting cervical lesions, but the false positive rate might be greater compared to that of $\mathrm{LBC}$, which was in agreement with the current screening experiences at home as well as abroad. ${ }^{39}$ Their study also showed that sensitivity of combination of LBC plus HPV was moderate $80.7 \%$, but the specificity and accuracy $(83.5 \%$ and $83.1 \%)$ were the highest in comparison to LBC and HPV; similar results being reported in a meta-analysis by Lim KM et al. ${ }^{40}$ This creates an enigma about the use of combination of LBC plus HPV. And also the use of both the tests for screening may entail more economic burden on the society. ${ }^{33}$ However, future researches are warranted for the same.

One of the limitations of the study was that patients included in the study had higher risk of cervical cancer compared to the general population, due to which it was unable to assess overdiagnosis of cervical precancers or probabilities of their progression.

\section{Conclusion}

The addition of high risk HPV DNA improved the sensitivity of LBC significantly. Co-testing was found to have the highest sensitivity $(98.80 \%)$ in predicting preinvasive and invasive lesion of cervix but the specificity was much reduced. Though the early detection and treatment of preinvasive and invasive lesion of cervix is required, it is important that the best and most sensitive diagnostic tools are used for the screening purposes. Overall HPV DNA was best predictor of pre-invasive or invasive lesion with significantly higher diagnostic accuracy as compared to cotesting.

\section{Conflict of interest: None. Disclaimer: Nil.}

\section{References}

1. WHO. Human papillomavirus (HPV) and cervical cancer. Geneva: World Health Organization. 2014.

2. WHO. Human papillomavirus (HPV) and cervical cancer. Geneva: World Health Organization. 2020. Available from https:// www.who.int/news-room/factsheets/detail/human-papillomavirus-(hpv)-and-cervicalcancer [Accessed August 2020].

3. Scarinci IC, Garcia FA, Kobetz E, Partridge EE, Brandt $\mathrm{HM}$, Bell MC, et al. Cervical cancer prevention. Cancer. 2010;116: 2531-42.

4. Peto J, Gilham C, Fletcher O, Matthews FE. The cervical cancer epidemic that screening has prevented in the UK. Lancet. 2004;364:249-56.

5. Taylor R, Morrell S, Mamoon H, Wain G, Ross J. Decline in cervical cancer incidence and mortality in New South Wales in relation to control activities (Australia). Cancer Causes Control. 2006;17:299-306.

6. Aminisani N, Armstrong B, Egger S, Canfell K. Impact of organised cervical screening on cervical cancer incidence and mortality in migrant women in Australia. BMC Cancer. 2012;12:491.

7. Mishra G. Cervical cancer screening and its implications on cancer prevention. In: Studd J, Tan LS, Chervenak AF (Eds). Current Progress in Obstetrics \& Gynaecology. $1^{\text {st }}$ edition. New Delhi: Tree life media. 2012. pp. 339-48.

8. Hutchinson ML, Cassin CM, Ball HG. The efficacy of an automated preparation device for cervical cytology. Am J Clin Pathol. 1991; 96: 300-5.

9. Gibb RK, Martens MG. The impact of liquid-based cytology in decreasing the incidence of cervical cancer. Rev Obstet Gynecol. 2011; 4: S2-S11.

10. Boulet GA, Horvath CA, Berghmans S, Bogers J. Human papillomavirus in cervical cancer screening: important role as biomarker. Cancer Epidemiol Biomarkers Prev. 2008; 17: 810-7.

11. Mayrand MH, Duarte-Franco E, Rodrigues I, Walter SD, Hanley J, Ferenczy A, et al. Human papillomavirus DNA versus Papanicolaou screening tests for cervical cancer. N Engl J Med. 2007; 357: 1579-88.

12. Wright TC, Denny L, Kuhn L, Pollack A, Lorincz A. HPV DNA testing of self-collected vaginal samples 
The New Indian Journal of OBGYN. 2021 (January-June);8(2)

compared with cytologic screening to detect cervical cancer. JAMA. 2000; 283: 81.

13. Schiffman M, Herrero R, Hildesheim A, Sherman ME. HPV DNA testing in cervical cancer screening: Results from women in a high-risk province of Costa Rica. JAMA. 2000; 283: 87.

14. Franceschi S. Monitoring HPV16/18 immunisation in England and elsewhere. Br J Cancer. 2010; 103: 157-8.

15. WHO. Comprehensive cervical cancer control-A guide to essential practice. 2nd edition. Geneva: WHO Press; 2014.

16. AIHW. Cervical screening in Australia 2012-2013 Cancer series no.93. Cat. no. CAN 91. Canberra: Australian Institute of Health and Welfare; 2015.

17. Farhad A, Rainer K, Belaynew W. Understanding cervical cancer in the context of developing countries. Annals of Tropical Medicine and Public Health. 2012; 5(1): 3-15.

18. Murillo R, Almonte M, Pereira A, Ferrer E, Gamboa OA, Jerónimo J, et al. Cervical Cancer Screening Programs in Latin America and the Caribbean. Vaccine. 2008; 19 (Suppl 11): L37-48.

19. Ma Y, Di J, Bi H, Zhao Q, Qin T, Xu W, et al. Comparison of the detection rate of cervical lesion with Tru Screen, LBC test and HPV test: A Real-world study based on population screening of cervical cancer in rural areas of China. PLoS One. 2020; 15(7): e0233986.

20. Anttila A, von KL, Aasmaa A, Fender M, Patnick J, Rebolj M, et al. Cervical cancer screening policies and coverage in Europe. Eur J Cancer. 2009; 45(15): 2649-58.

21. Arbyn M, Anttila A, Jordan J, Ronco G, Schenck U, Segnan N, et al. European Guidelines for Quality Assurance in Cervical Cancer Screening. Second edition-summary document. Annals Oncol. 2010; 21(3): 448-58.

22. Murillo R, Wiesner C, Cendales R, Piñeros M, Tovar S. Comprehensive evaluation of cervical cancer screening programs: the case of Colombia. Salud pública de México. 2011; 53(6): 469.

23. Chinaka CC, Abudullahi M, Mohammed OM. A comparative study on the use of liquid based. cytology and conventional pap smear in cervical screening. J Med Med Res. 2014; 2(4): 40-50.

24. Junyangdikul P, Tanchotsrinon W, Chansaenroj J, Nilyaimit P. Clinical prediction based on HPV DNA testing by hybrid capture 2 (HC2) in combination with liquid-based cytology (LBC). APJCP. 2013; 14(2): 903-7.

25. Karimi-Zarchi M, Peighmbari F, Karimi N, Rohi M, Chiti Z. A comparison of 3 ways of conventional pap smear, liquid-based cytology and colposcopy vs cervical biopsy for early diagnosis of premalignant lesions or cervical cancer in women with abnormal conventional pap test. IJBS. 2013; 9(4): 205-10.

26. Ronco G, Segnan N, Giorgi-Rossi P, Zappa M, Casadei GP, Carozzi F, et al. Human papillomavirus testing and liquid-based cytology: results at recruitment from the new technologies for cervical cancer randomized controlled trial. J Natl Cancer Inst. 2006; 98(11): 765-74.

27. Gopal N, Joshi PS, Pukale R, Shamashoor. Colposcopic findings in unhealthy cervix and its comparision with cytology and histopathology. J Evol Med Dental Sci. 2013; 2(26): 4663-71.

28. Suguna M, Rajeshwar A, Pasula S. Study on Pap smear and coloposcopy in unhealthy cervix in women. Int $\mathrm{J}$ Med Sci Public Health. 2014; 3(5):1.

29. Mukherjee BN, Sengupta S, Chaudhuri S, Biswas LN, Maiti P. A case-control study of reproductive risk factors associated with cervical cancer. Int J Cancer.1994; 59: 476-82.

30. Zhao FH, Lin MJ, Chen F, Hu SY, Zhang R, Belinson JL, et al. Cervical Cancer Screening Group in China. Performance of high-risk human papillomavirus DNA testing as a primary screen for cervical cancer: a pooled analysis of individual patient data from 17 populationbased studies from China. Lancet Oncol. 2010; 11(12): 1160-71.

31. Ashmita D, Shakuntala PN, Rao SR, Sharma SK, Geethanjali S. Comparison and correlation of PAP smear, colcoscopy and histopathology in symptomatic women and suspicious looking cervix in a tertiary hospital care centre. Int J Health Sci Res. 2013; 3: 50-9.

32. Sankaranarayanan R, Budukh A, Rajkumar R. Effective screening programmes for cervical cancer in low and middle- income developing countries. Bulletin World Health Organization. 2001; 79: 954-62.

33. Massad LS, Einstein MH, Huh WK, Katki HA, Kinney WK, Schiffman M, et al. 2012 Updated consensus guidelines for the management of abnormal cervical cancer screening tests and cancer precursors. J Low Genit Tract Dis. 2013; 17(Suppl 1): S1-S27.

34. Agorastos T, Dinas K, Lloveras B, de Sanjose S, Kornegay JR, Bonti $\mathrm{H}$, et al. Human papillomavirus 
The New Indian Journal of OBGYN. 2021 (January-June);8(2)

testing for primary screening in women at low risk of developing cervical cancer. The Greek experience. Gynecologic Oncol. 2005; 96: 714-20.

35. Ogilvie GS, Krajden M, van Niekerk DJ, Martin RE, Ehlen TG, Ceballos K, et al. Primary cervical cancer screening with HPV testing compared with liquid-based cytology: results of round 1 of a randomised controlled trial -- the HPV FOCAL Study. Br J Cancer. 2012; 107(12):1917-24.

36. Ramesh G, Sudha R, Jayashree AK, Padmini J. Colposcopic evaluation of unhealthy cervix. J Clin Diagn Res. 2012; 6:1026-8.

37. Parvin S, Kabir N, Lipe YS, Nasreen K, Alam KM. Correlation of Pap smear and colposcopic finding of cervix with histopatholgiocal report in a group of patient attending in a tertiary hospital. J Dhaka Med Coll. 2013; 22(1): 39-44.

38. Wang J. Analysis of the application values of different combination schemes of liquid-based cytology and high- risk human papilloma virus test in the screening of highgrade cervical lesions. Braz J Med Biol Res. 2018; 52(1): e7517.

39. Brown AJ, Trimble CL. New technologies for cervical cancer screening. Best Pract Res Clin Obstet Gynaecol. 2012; 26(2): 233-42.

40. Li KM, Yin RT, Kang DY. Diagnostic accuracy of human papillomavirus test for cervical neoplasia: a systematic review of randomized controlled trials. Chin J Evidence-Based Med. 2011; 11: 910-8.

\section{Shreya Raj ${ }^{1}$, Mala Srivastava ${ }^{2}$}

${ }^{1}$ Senior resident at Dr Baba Saheb Ambedkar Medical College and Hospital, New Delhi, India; ${ }^{2}$ Senior

Consultant, Department Of Obstetrics and

Gynaecology, Sir Ganga Ram Hospital, New Delhi, India. 